be, if not "antagonistic to Darwin's theory of Natural Selection," at all events, as I expressed it, "an important emendation of Darwinism." My object, therefore, while reviewing the essay was to show that this is a character which does not belong to it. If I have misunderstood the meaning of its author on this fundamental point, I should have been glad to have received a more express statement of the fact than appears in the above letter; for I might then have felt that Mr. Dixon's views with reference to the value of his work are in full accordance with my own. As stated in the review, I consider his facts most interesting as examples of trivial specific characters-or slight variations of a fixed kind-due to variation presumably unaided by selection; and when I said that such facts " may be freely presented to the anti-Darwinians," I meant that they might be so presented to any one who supposed them anti-Darwinian. It appeared to me that Mr. Dixon himself regarded them in this light (though not as anti-evolutionary), at all events to the extent of imagining that they had not been sufficiently recognised by Darwinians. But, as I have said, if such is not his meaning, I am very glad to find myself in agreement with him upon this point.

I spoke of these trivial specific characiers as "odds and ends," and as of "comparatively rare occurrence," because, although both numerous in themselves and of importance for the purposes of detailed classification, they are insignificant when compared with the whole organising work of natural selection. And if, as Mr. Dixon now repeats, it was the object of his little book "to try and explain the agents" (i.e. the causes) producing these non-purposive specific characters, I can only repeat that in this respect his book has failed in its object. Lastly, my only reason for not mentioning Mr. Dixon's views on natural selection, \&c., was that I found nothing in these views particularly deserving of mention.

GEORGE J. ROMANES

\section{On Radiation of Heat from the Same Surface at Different} Temperatures

WITH respect to my recent communication to you on the subject of radiation of heat at different temperatures (p. 85), I wish to remark that the temperature given as the temperature of the surroundings must be taken as only approximate. A remark to this effect was in fact included in the first draft of my note to you, and was inadvertently omitted in the final copy.

If the glass envelope surrounding the wire were perfectly diathermanous, and likewise the intervening air, then the temperature of the surroundings would be simply that of the walls of the room. As it was there is a great difficulty in saying pre cisely what is to be taken as the temperature of the surroundings. The glass envelope becomes heated to some extent, and will return a certain amount of radiation to the wire. When the vacuum is nearly complete, however, the heating of the glass is slight, and is very small in comparison with the heating when the vacuum is only partial.

The reason I have not used a metallic envelope blackened inside and cooled outside, is that it is very difficult to attach such an envelope in a satisfactory way to the Sprengel pump. I am, however, hopeful of being able to overcome this difficulty.

November 28 J. T. BOTTOMLEY

\section{THE NOVEMBER METEORS}

THE watch which was kept on November 27 in the hopes of seeing a shower of meteors from the stream connected with Biela's comet was very amply rewarded. At the Royal Observatory, Greenwich, the weather was somewhat unfavourable, the sky being partly clear only at intervals, yet, when the meteors were first seen, between $6 \mathrm{~h}$. and $7 \mathrm{~h}$. p.m., they were appearing at the rate of from 30 to 40 per minute. The average brilliancy of the meteors was remarkable. The radiantpoint as determined at the Greenwich Observatory from a number of paths was estimated to be about R.A. $20^{\circ}$, Decl. $49^{\circ} \mathrm{N}$.

We have received the following communications with reference to the meteor showers :-

THE great display of Andromedes, or meteors of Biela's comet, which occurred on the evening of November 2'7 last, and which fortunately has been widely observed, adds another corroborative link to the theory, already demonstrated by facts, connecting comets and meteors. Not only does this stream exhibit a perfect orbital resemblance to that of the comet with which it has been associated, but it recurs only at the special times when, according to computation, the comet is in the vicinity of that region of its orbit encountered by the earth on November 27.

Many meteors appeared on the evening of November 26 this year, the hourly rate, as estimated at Bristol, being considerably over Ioo, and they nearly all belonged to the shower from Biela's comet. But the display on that night was not of very exceptional richness, though it gave distinct intimation of what was to follow. The meteors of November 26 were simply the avant couriers of the advancing host, for, as soon as twilight deepened on the following evening, it was seen at once that the shower had greatly intensified. Meteors were falling so thickly as the night advanced that it became almost impossible to enumerate them. Frequently they came in simultaneous groups of five, seven, or ten, all radiating from the immediate region of the star $\gamma$ Andromedæ, and appeared in every quarter of the firmament with that uniform slowness of movement which is a peculiar feature of the shower.

The prediction that such a display would occur has thus been completely verified, and the character of its leading features has been precisely conformable to anticipation. For not only has a meteor-shower occurred at the appointed time, but it has coincided in all its salient attributes with what has been expected. The radiantpoint near $\gamma$ Andromedæ has been accurately marked, as on November 27,1872 , and the meteors have presented the same visible traits of appearance.

As to the strength of the display, it has been variously described, but there can be no doubt, from the observations, that it will rank in importance with any similar phenomenon recorded in modern times. At stations where the clearness of the atmosphere permitted its full grandeur to be recognised, it would seem that about one meteor per second was counted, and this means a rate of 3600 per hour.

These facts warrant us in the assumption that the earth has recently encountered a very dense region of the meteor-stream. Notwithstanding that these meteors have to overtake the earth in her orbit, and that they therefore travel with the minimum velocity (about eleven miles per second) possible in the case of such bodies, they have returned in surprising abundance. A far more attenuated system, encountering the earth under similar conditions to the Leonids of November 13, which directly meet the earth in her path, must have originated a more numerous display, because a far greater range of such a stream would be traversed in the same interval. Here the velocities of the earth and meteors would be combined by the favourable circumstances of the rencontre, and the earth would really penetrate the stream at the rate of some forty-four miles per seconcl. But in the instance of the meteors from Biela's comet, they are travelling in the same general direction as ourselves, and it is only their greater native velocities which enable them to catch up the earth, and become visible in the form under which we have just observed them.

When all the accounts of this remarkable display become available for reduction, it will be important to compare them with those of its predecessor in November, I 872 . Though the present shower has been an obvious repetition of the one just referred to, it may exhibit some differences which it will be essential to investigate. In one respect certainly there would appear to be a want of accordance. We refer to the relative durations of the two displays. In 1872 , on November 26 and 28 , that is, on the nights preceding and following the great shower, very little sign of it appears to have been observed. It was 